This item was submitted to Loughborough's Research Repository by the author.

Items in Figshare are protected by copyright, with all rights reserved, unless otherwise indicated.

\title{
Material inspiration: from practice-led research to craft art education
}

PLEASE CITE THE PUBLISHED VERSION

http://dx.doi.org/10.1386/crre.1.63_1

PUBLISHER

(c) Intellect

VERSION

AM (Accepted Manuscript)

LICENCE

CC BY-NC-ND 4.0

REPOSITORY RECORD

Nimkulrat, Nithikul. 2019. "Material Inspiration: From Practice-led Research to Craft Art Education". figshare. https://hdl.handle.net/2134/8623. 
This item was submitted to Loughborough's Institutional Repository (https://dspace.lboro.ac.uk/) by the author and is made available under the following Creative Commons Licence conditions.

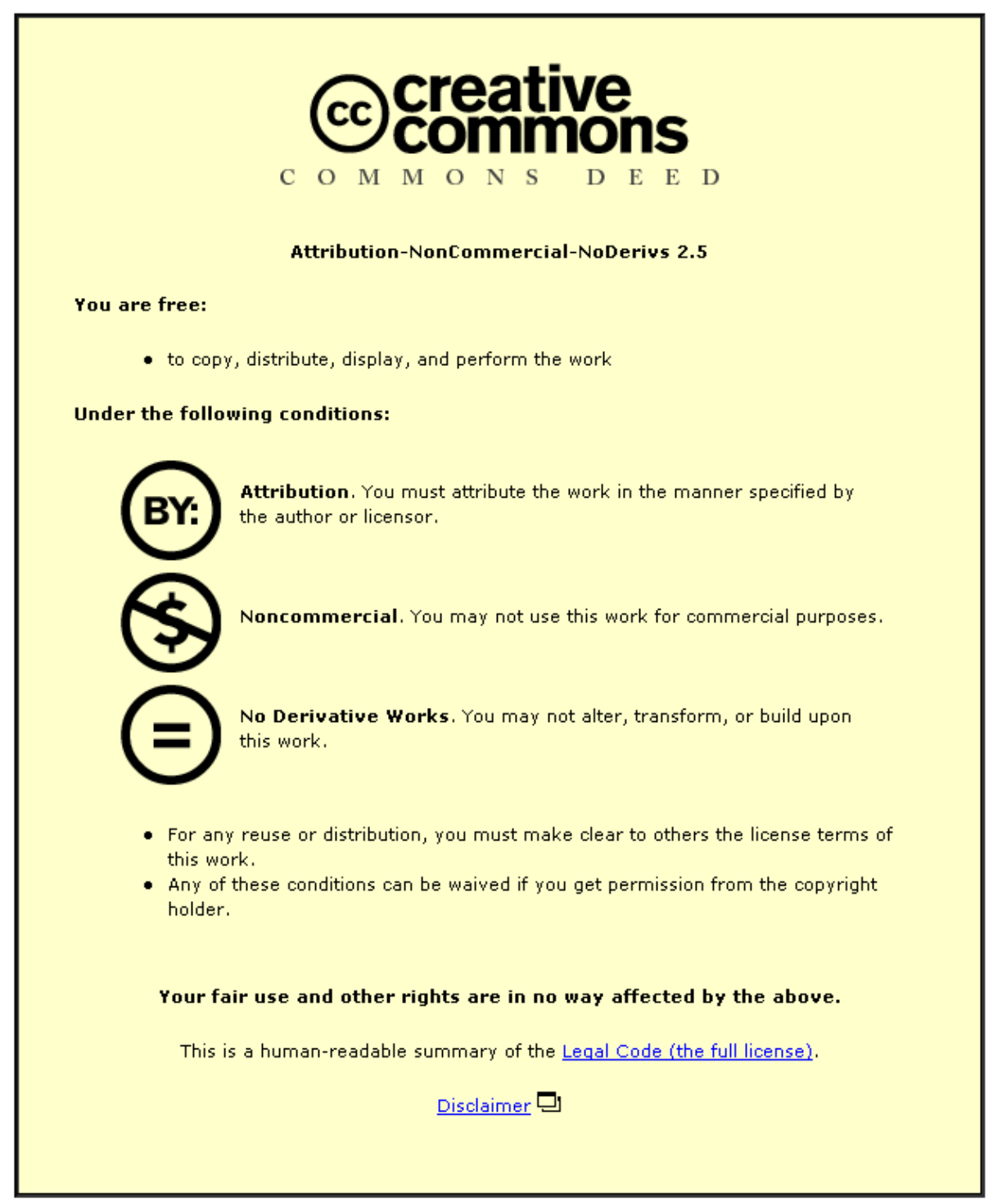

For the full text of this licence, please go to: http://creativecommons.org/licenses/by-nc-nd/2.5/ 


\title{
Material inspiration: From practice-led research to craft art education
}

\section{Nithikul Nimkulrat}

\begin{abstract}
Craft art discourse has centred on the use of physical materials. In Finland, craft art students are trained to understand various techniques and the materiality of their chosen medium. However, the materiality is often taught in terms of physical properties (e.g. tensile, elasticity, etc.). Conceptual or expressive properties (e.g. feel, impression, etc.) are hardly discussed and it is left to students to experiment with these properties in their studio practice. The conceptual issues of craft art practice concerning the use of materials thus remain personal and implicit. This article illuminates how the conception of 'materialness' generated from within practice-led research in textile art can stimulate students' creativity in relation to physical materials and enable them to design the meaning and aesthetic of their work more intentionally. The consideration of materialness can thus serve as a useful means for textile artists and other craft artists in creating meaningful artworks with any chosen materials.
\end{abstract}

\section{Keywords}

materiality

expressivity

practice-led research

reflective practice

textile art 


\section{Introduction}

Craft art discourse has been identified and categorized by materials (e.g. ceramic, glass, wood and textile). Where the term pertains to a craft art area, it implies that tangible materials are fundamental for the creation of any work in that area (e.g. textile art defines craft art that uses textiles, yarns and fibres as material). Aiming to emphasize the importance of materials in creation processes, this article uses the term 'craft art' to identify an artistic practice that utilizes craft as the thinking process to create material artworks. This follows Glenn Adamson's notion of craft as 'a way of thinking through practices of all kinds' (Adamson 2007: 7).

One problem that craft art (or 'fine craft' in Risatti's term (Risatti 2007: 303)) has encountered is grounded in its 'fore-understanding' or 'the complex of ideas ... that make up the individual's realm of understanding' (Risatti 2007: 277). Fore-understanding that surrounds the practical matters of materials and techniques means that craft art practice is often recognized as making things by hand and as less theoretical than fine art (Risatti 2007: 303-306). Influenced by this fore-understanding, discussion on craft art often concerns techniques for manipulating a material in order to make a tangible object. Materials seem to serve as physical entities while their conceptual problems have been little considered.

In textile art, with which I am concerned here, education has emphasized practical training over providing a theoretical and conceptual basis. For example, in Finnish universities, textile pedagogy is usually structured around learning technical skills. The materiality of the medium is taught in terms of physical properties (e.g. tensile, elasticity, etc.). Conceptual or expressive properties (e.g. feel, impression, etc.) are hardly discussed and it is left to students to experiment with these properties in their studio practice. Skills lead a creative process, which then continues with choosing a material to suit the technique, i.e. materials function as supporting the capability of techniques. Over-emphasizing textile techniques can restrict the textile artist's way of thinking, especially if they are a novice, and easily limit the variety of materials that they can use with each technique. For example, a student majoring in weaving might think only about using materials in the form of yarn on a weaving loom, or a student skilful in printing might think about silk-screening a pattern only on the flat surface of a fabric. This easily limits the variety of materials that can be used for each technique. 
Based on Nigel Cross's thinking (1982: 221-227, 1999: 49-55) that the knowledge of creative practice exists in the creator, the artefact and the process, creative practitioners know what they are doing in a creative process and why they are doing it. Their way of knowing is situated in their action and experience. This also applies for textile artists who gain professional competence through making material artworks. However, while there is an understanding of the importance of knowing in action, the crucial role of material understanding for the creative process, and the development of the resulting works, is rarely articulated. This article shifts the focus from the end result, the beautiful object, to the conceptual value of the creative process, i.e., how to give the object meaning through working with material.

In order to improve the fore-understanding of craft art, an explicit discourse on the ways craft artists think through creative processes is needed. Literature on textiles has markedly increased during the last decade with edited books and monographs (e.g. Gale and Kaur 2002, Rowley 1999, Jefferies 2001, Sharrad and Collett 2007) as well as academic journals on textiles (e.g. Textile: The Journal of Cloth and Culture, first published in 2003 and DUCK: Journal for Research in Textiles and Textile Design, first published in 2010). Despite this increase, the majority of literature is written by or from the point of view of historians, educators or curators, with few texts by textile artists (e.g. Andrew 2008: 32-65, Lukkarinen 2008), and the literature on the conceptual properties of materials in textile art practice remains rare.

This article aims to illuminate how the conception of 'materialness' or 'thinking through materials' generated from within practice-led research in textile art (Nimkulrat 2009) can stimulate students' creativity in relation to physical materials. Materialness suggests the totality of craft art creation rooted in material, demonstrating how a tangible material can participate actively in deriving the form, content, context and time of a craft artwork. Through these elements, the concept of materialness enables craft artists to convey an intended meaning to other people. Materialness relates a tangible physical material with artistic expression, shaping the total artistic process of craft art in which material and its interaction with the craft artist play the vital role. On the one hand, materialness leads the skilful hand and the sensitive mind of the craft artist to reflect on and execute the resulting works in a particular fashion, and to already begin to think about a suitable choice of 
exhibition space during the creative process. On the other, it directs the viewers of the craft artworks to relate their current experience with the artworks in the exhibition space to themselves and their earlier experiences. The concept of materialness thus helps the artist to communicate their intentional idea to the audience.

\section{Exploring the relationship of materiality and expressivity in textile art: A practice-led study}

Textile materials can be the subject of research, such as the study of inventing a new material or improving an existing material from the viewpoint of material scientists. The subject of interest here is the meaning of material beyond touchable and visible qualities. Understanding the intangible aspects of a material entails scrutinizing actual textile art practice that uses the material as medium. As a textile artist, one possible way to investigate actual textile art practice is to adopt the role of a 'reflective practitioner' (Schön [1983] 1995), who not only works with the material in question, but also scrutinizes and reflects on the resulting works and their creations as case studies. The criteria for this study's material selection are: (1) use of a material not used by the textile artist before and (2) a non-textile material used previously by other textile artists. Paper string was chosen based on the aforementioned criteria. Paper string is not a new material for craft art per se but it served as an example for studying how a material can influence a craft artist, her creative process and resulting works. It enabled myself, as the researcher, to experience a new material and to compare my experience with another textile artist.

The examination of the expressive qualities of paper string gives rise to the question: how does paper string as material play a role in the creative process? It is evident that the material constructs a physical object of textile art. The question is whether it can also construct and express the object's meaning, and if so, how? These questions were investigated in depth in Paperness: Expressive Material in Textile Art from an Artist's Viewpoint (Nimkulrat 2009) to elicit the relationship between physical-material and artistic expression within craft production. The research elucidated the influence of paper string and its expressive qualities on the experience and thoughts of both the textile artist during her creative process and the viewers during their contemplation. The key findings from this Ph.D. study are presented in this article. 
Research through one's own creative practice, or practice-led research, suggests an approach where the practitioner takes the position of the researcher using his/her own professional practice as a means of inquiry (Rust et al. 2007). In order to discuss in detail my craft productions, this research utilized making and exhibiting craft artworks as one of the approaches (figure 1). As the craft artworks made of paper string were displayed in galleries, knowing how viewers looked at the material assisted in investigating the relationship between materiality and expressivity of paper string. This aspect supported the choice of questioning visitors to the exhibitions. Questioning also included an interview with a textile artist who has used paper string to create her textile art. Where appropriate, the craft productions or information gathered from the visitors' questionnaires and the interview were contextualized through relevant literature to provide a more comprehensive explanation.

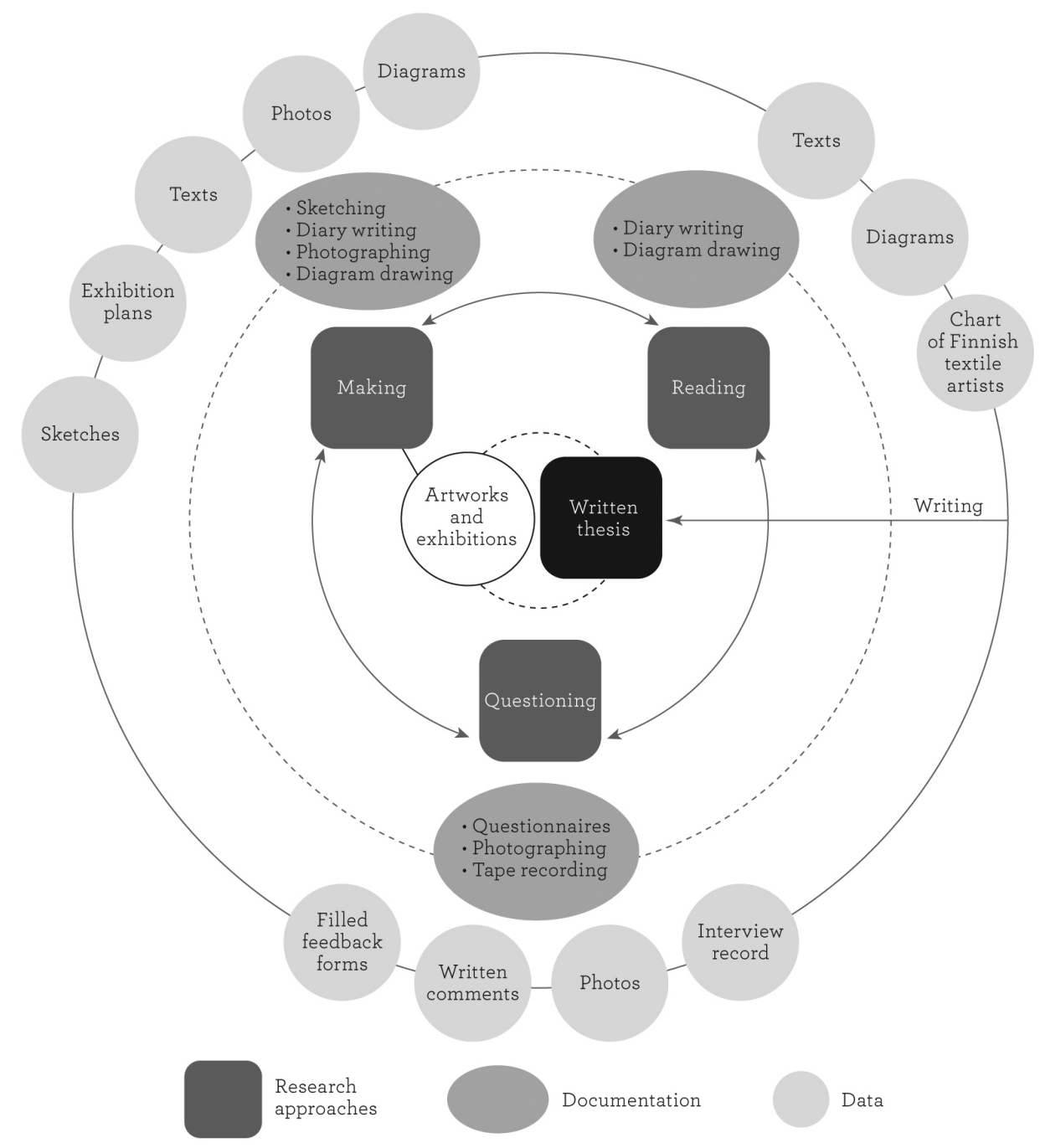

Figure 1: Nithikul Nimkulrat (2 February 2009), Diagram of the dialogue between research approaches, means of documentation and data collection, (C) Nithikul Nimkulrat. 
To study paper string's expressive qualities, the material was used to create craft artworks, which were publicly displayed in two exhibitions: 'Seeing Paper' (figure 2) and 'Paper World' (figure 3). Works in both exhibitions were designed and produced around the research problem. The productions, exhibitions and craft artworks generated visual and textual data for analysis and formed the key component to the steps taken towards understanding the research topic.

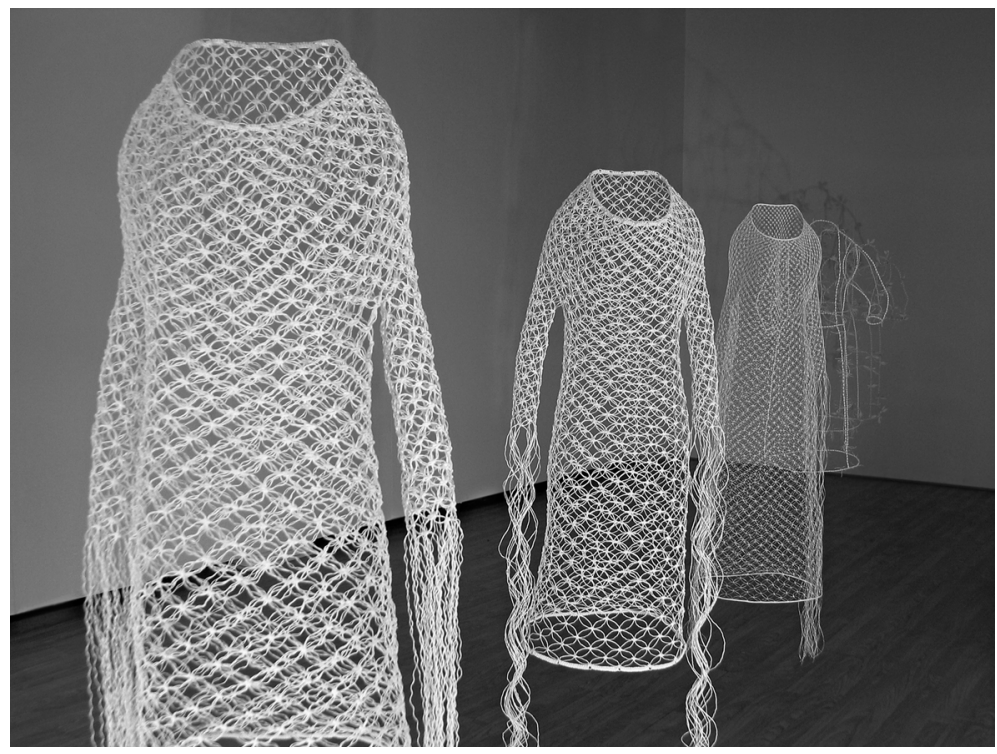

Figure 2: Nithikul Nimkulrat (5 June 2005), 'Seeing Paper', photograph by Maj Lundell, (C) Nithikul Nimkulrat.

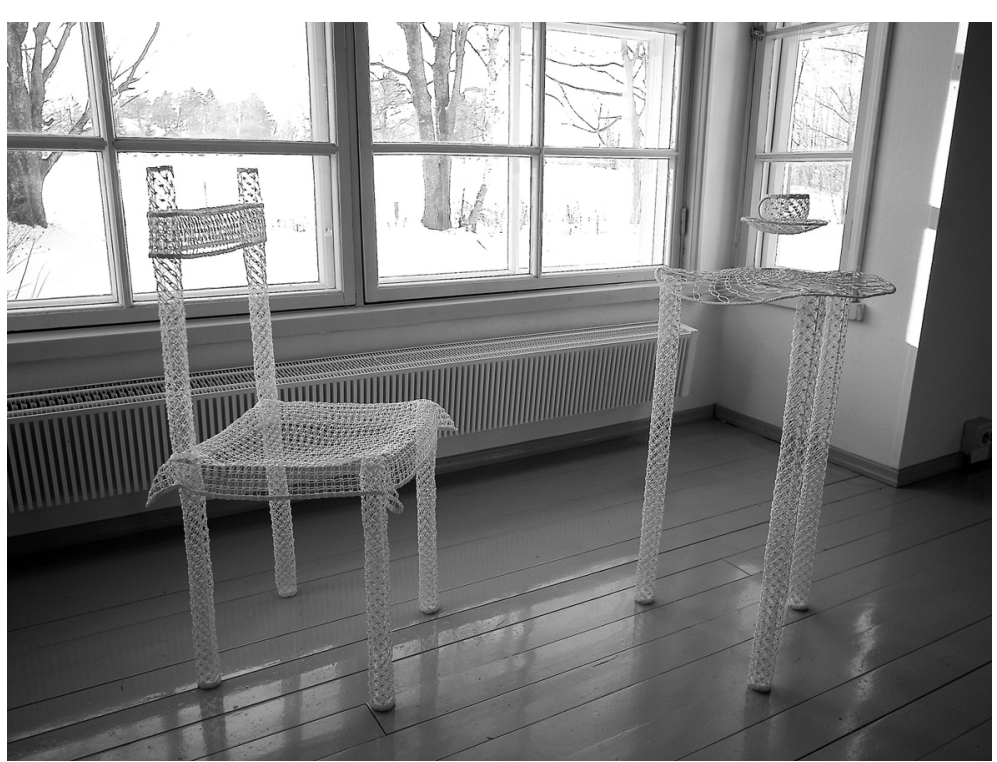

Figure 3: Nithikul Nimkulrat (7 February 2007), 'Paper World', photograph by Phakphum Julnipitawong, (C) Nithikul Nimkulrat. 
'Seeing Paper' explored the influence of different physical qualities of paper string on the creative process. It also examined the expressive qualities of the craft artworks as influenced by their materials. Three types of paper string in white colour with distinct visual and tactile qualities were chosen (figures $4 \mathrm{a}, \mathrm{b}$ and $\mathrm{c}$ ). While their visual differences included form (e.g. straight/curly), their tactile differences, which were almost visually indistinguishable, consisted of strength (strong/weak) and texture (e.g. rough/smooth). The set of three types of paper string was used together with two knotting techniques to construct two series, each consisting of three craft artworks (figures $5 \mathrm{a}, \mathrm{b}$, and $\mathrm{c}$ and figures $6 \mathrm{a}, \mathrm{b}$ and $\mathrm{c}$ ). In each series, colour, technique and mould were fixed factors, whereas the material factor was variable. This allowed studying the effect of dissimilar types of paper string on the resulting works. 'Seeing Paper' demonstrated the influence of the physical qualities of paper string on the craft artist's feelings and thoughts - thoughts that form the artistic process and interpretations of the ongoing works (Nimkulrat 2007a: 17-24; 2009: 105-128). For example, one of the three types of paper string (figure $4 \mathrm{~b}$ ) is originally sturdy, straight and smooth. This material was used after being untwined and separated into smaller strings. Untwined strings appeared curly and were tactually coarse. When hand-knotting the untwined strings to form Get Sorted (figure 5b), I realized that pulling could break the strings. This unexpected experience changed my understanding of the materiality of this material and seemed to stimulate my creativity. The material's hidden fragility and visible coarseness influenced my thoughts and shaped my interpretation of the work, leading to the title Get Sorted. The experience of the broken strings and the coarse texture led to the association with an earlier experience of something else - barbwire. The association facilitated the creation process of Private Area (figure $6 \mathrm{~b}$ ) that also used this material. Forcefully pulling the strings to break them became the main manipulation that made the material's qualities visible as the key feature of the work. As Merleau-Ponty ([1962] 2005: 369) stated, a tactile phenomenon is effective when it finds something similar within the person who touches. The above example shows how the tactile experience gained through the craft artist's hand can seek connection with consciousness and evoke the memory of prior experiences.

In spite of this, when 'Seeing Paper' was displayed in a modernist gallery, most visitors' comments showed that the differing physical qualities seemed to have little influence on their interpretation of the exhibits. I reflected on this shortcoming and inferred that the following factors might have caused it: first, the white space of the modernist gallery significantly influenced the viewers contemplating the artworks (O’Doherty 1999: 79), so that they hardly 
recognized the visual differences in material qualities. Second, the differences between the qualities of paper string might be too subtle. Third, the viewers experienced the overall exhibition rather than the details of the exhibits. Merleau-Ponty ([1962] 2005: 3-9, 77-83) and Heidegger ([1988] 1999: 69-70) deal with this phenomenon explaining that one experiences a thing within a spatial temporal context. The act of seeing includes other coexisting objects in the space, which can refer to one another and create a significant whole. Consequently, 'Paper World' extended the study to the issues of paper string's potential to express certain contexts, both during its creation and exhibition (Nimkulrat 2009: 128-150). A type of paper string, which has the same strength, texture and straightness as one of the three types used in 'Seeing Paper' (figure 4a), was chosen for the creation of all works. The works were created in relation to one another and the exhibition context (figures 3 and 7) including the local culture in which the exhibition took place. This way of working expanded the understanding of paper string, i.e., the material could be understood in a context, not as a single entity separated from its surroundings. This changing understanding informed what the artist could transform the material into and how the material could construct the meaning of the overall exhibition. For instance, the creation of 'Paper World' examined the meaning of paper string in Finland. In the history of Finnish craft during the post-war period (the 1940s1950s), paper string was the major material used to make products, such as shoes, clothes, curtains and many other items necessary for everyday life (Kruskopf 1975: 73; Priha 1999: 124; Singleton 1986: 62). The historical everydayness of the material stimulated my creativity, leading 'Paper World' to express the meaning of paper string in the past through the forms of useful objects. To determine the choice of the exhibition context, I adopted the role of a viewer; this was to follow Dewey's thought ([1934] 2005: 48-56) that if the artist undertakes the attitude of a viewer while making artworks, in return the viewer would have to explore the artist's standpoint to understand what the artworks try to say. Due to this attitude, a residential home was converted into a gallery, because most people know the concept of home. The elements of the gallery's space informed me as to which functional forms my craft artworks could represent, e.g. a fireplace set for the existent fireplace (figure 7). Whiteness, fragility and other qualities of paper string constructed the meaning of the exhibition as imaginary home. Paper string influenced the way one sees the craft artworks in functional forms, indicating that the utilitarian functions are no longer applicable to them. The works not only represented the actual objects in everydayness but also emphasized the meaning of the objects represented, through the reproduction of the objects' basic characteristics, form and scale. During the exhibition, most visitor comments revealed that they understood the 
meaning of the exhibition and exhibits I had constructed. They experienced the craft artworks in the forms of functional objects differently from the actual ordinary artefacts, because of their uncommon material. This occurrence implied that a material has expressive potential to give new meaning to ordinary forms.
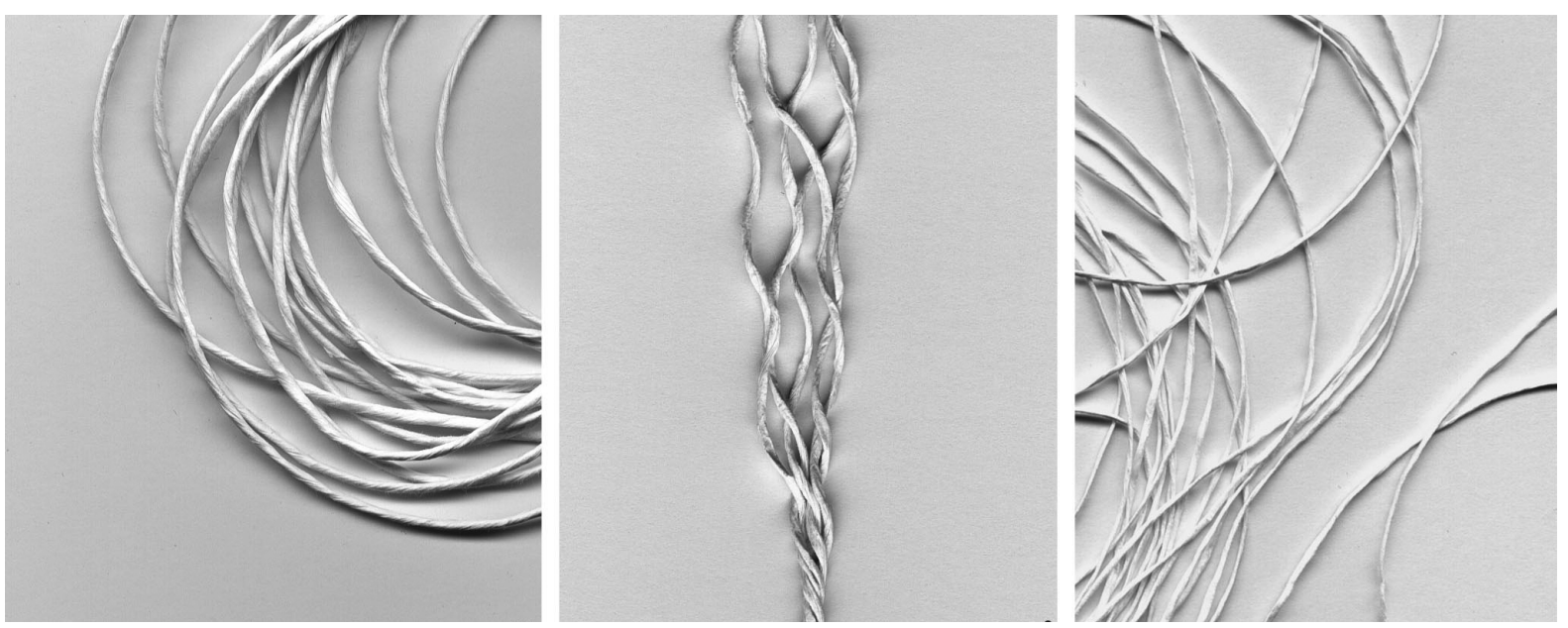

Figures 4a, b and c: (19 October 2009), Three types of paper string used to create 'Seeing Paper', photograph by Minna Luoma, CNithikul Nimkulrat.
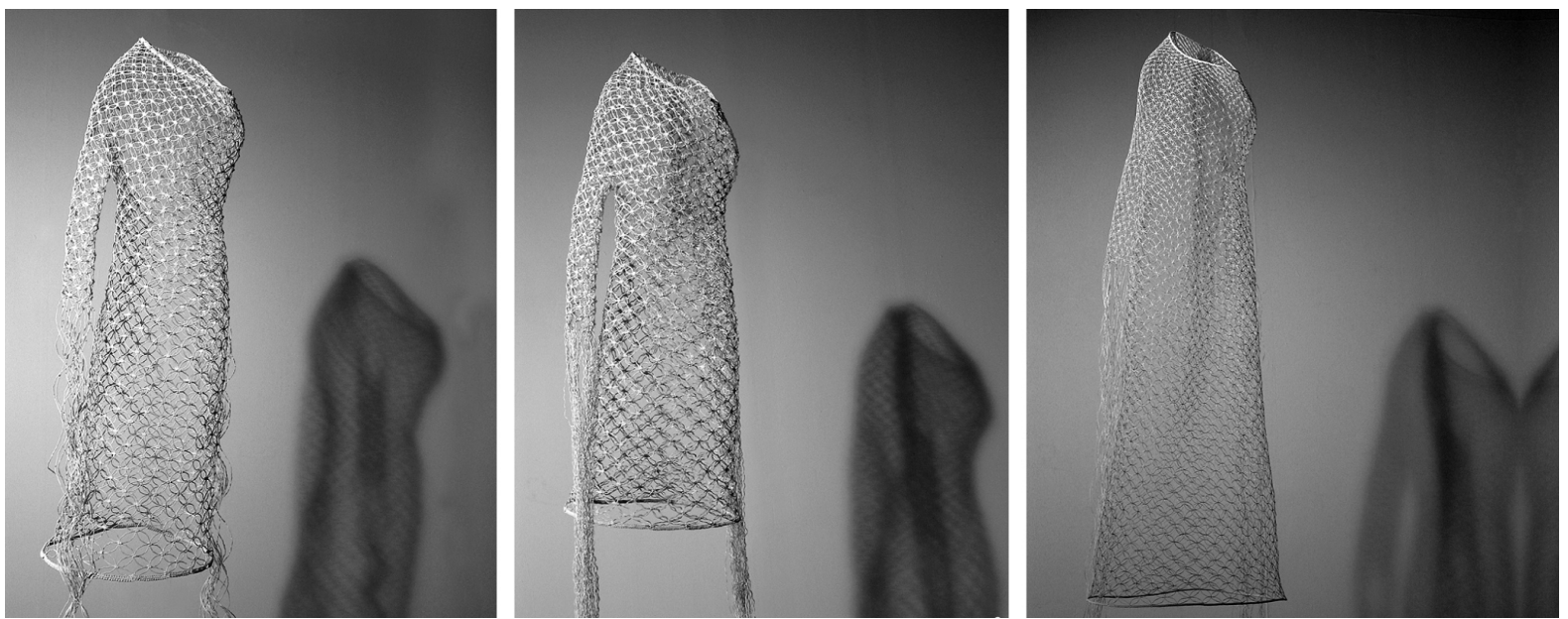

Figures 5a, b and c: Nithikul Nimkulrat (5 June 2005), from left: Let Go, Get Sorted and

Breathe Easily (each piece uses one of the three types of paper string presented in figures 4a, $\mathrm{b}$ and $\mathrm{c}$ with the same knotting technique), photograph by Maj Lundell, (C) Nithikul Nimkulrat. 

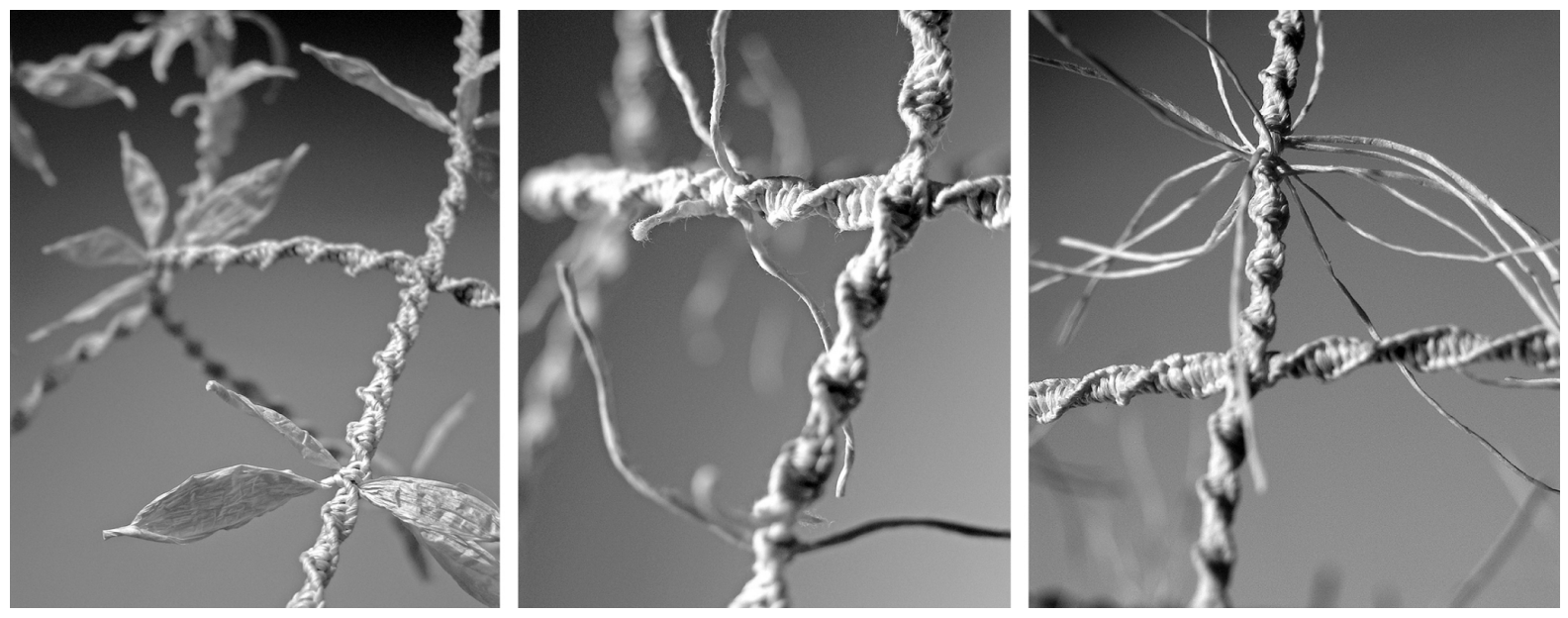

Figures 6a, b and c: Nithikul Nimkulrat (5 June 2005), from left: Private Garden, Private Area and Personal Joy (detail) (each piece uses one of the three types of paper string presented in figures $4 \mathrm{a}, \mathrm{b}$ and $\mathrm{c}$ with a different knotting technique), photograph by Maj Lundell, (C) Nithikul Nimkulrat.

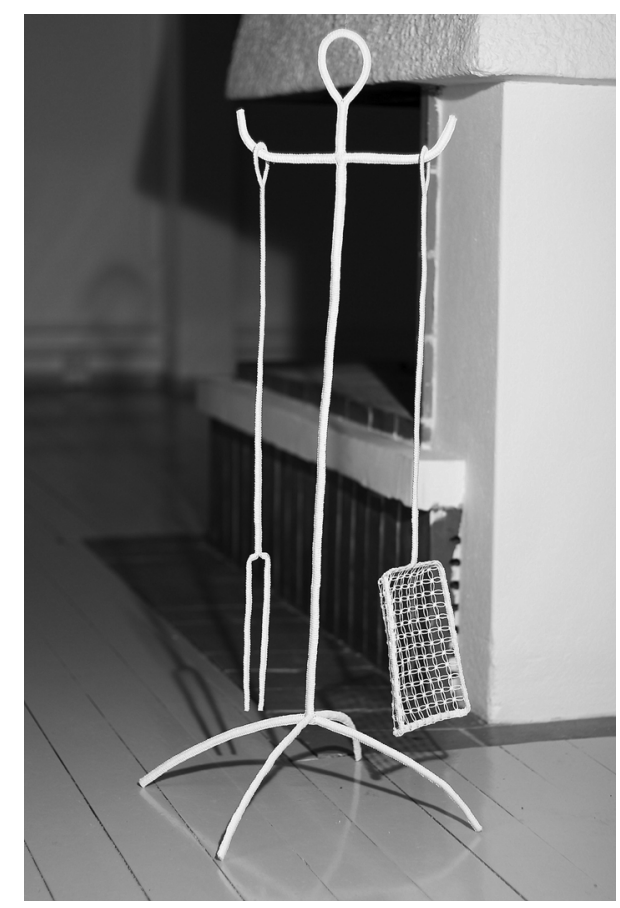

Figure 7: Nithikul Nimkulrat (7 February 2007), The Coal Rake (artwork created and installed with regard to an existing element of the gallery space) photograph by Phakphum Julnipitawong, (C) Nithikul Nimkulrat.

This study utilized various means of documentation, such as diary writing, diagram drawing, photographing and sketching (figure 1) to document the craft productions and the experience of making works by hand. The captured visuals and texts became the data, which was later 
organized, communicated and discussed. The implicit artistic experience becomes attainable and debatable in the context of disciplined inquiry because of documentation (Nimkulrat 2007b). Documentation makes the connection between creative and research practices possible. However, it can be considered a challenging part in conducting practice-led research. The researcher has to find a practical system to document the research process that can maintain a balance between creative and research practices. This means that documentation ought to be carried out in a system that least interrupts the flow of the creation and still captures the relevant occurrences in the process.

\section{Materialness: A conception from within practice-led research}

Research through one's own creative practice facilitates a thorough examination of the research problem. Before this study, the materials used in my textile art had never included paper string. Its conflicting characteristics interested me. On the one hand, it seems commonplace, as it is industrially produced in the form of yarn like other textile materials. On the other, it is special, because it is produced from wood, a raw material extensively available in Finnish nature.

By focusing on paper string, various themes have developed during the study, uncovering the active quality or expressivity of paper string in textile art, or what I call 'paperness'. Paperness (Nimkulrat 2009) demonstrates how a material is not limited to its physical qualities, but extends to the senses of bodily movement and the metaphorical modes of expression of the person experiencing the material. 'Materialness' can produce higher meaning. The meaning might arise both from the material per se within the creative process and from its contextual presentation in form of a craft artwork in an exhibition. In the studio context, meaning stems from the craft artist's sensory experience with a material. When hand-working with it, the craft artist feels the material's qualities, which, in return, gives inspiration for the (new) subject matter for the work. The craft artist shapes the material into forms that correspond to the content. In the exhibition context, the meaning derives from the viewers' visual experience of the complete craft artworks within the exhibition context. When walking around the exhibition to examine the works, the viewers seek relationship between themselves and what they are experiencing in order to interpret the meaning of the exhibition and exhibits. Material as presented in the craft artworks can influence the viewers' interpreting process operated in a particular time and space. My own craft productions 
(exemplified in the previous section) demonstrate how materialness extended beyond the touchable and visible qualities of paper string, so that meaning could arise from the material in different contexts: paper string per se and paper string as it is presented in craft artworks.

The practice-led process of the research has guided the choice of theoretical approaches. John Dewey's theory of expression ([1934] 2005) has informed the discussion of creative processes and-my experience with the chosen medium. Dewey ([1934] 2005: 60-109) maintained that the artist's action of resolving creative pressure through working with a particular medium manifests itself in the expression of the artwork.

Expression involves skilful control of a medium in order to make the artwork expressive or embody a meaning. As can be seen in 'Seeing Paper', the control of paper string to create a craft artwork engaged both a physical action to form a tangible object and an expressive act to incorporate a meaning into the object. The project showed that a material's physical qualities could affect both thoughts and feelings, especially when experiencing difficulties with the material. It also showed that having to overcome difficulties can unpack creativity and help express ideas by creating awareness of certain features of the material. The materialness of the medium can help relate artistic expression to the physical material of the craft artwork in the process. The resulting work embodies its maker's expressive and creative thought through its material-physical form.

Understood in this way, one may say that 'Making is thinking', i.e., the process of creating material artworks can be identified as one way of thinking, which is a cognitive activity (Sennett 2008: 149-153). Craft is a means for logically thinking through senses. When manipulating a tangible material, a craft artist establishes a rhythmic interplay between bodily and thinking practices. The craftwork of an artist is not secondary to thinking or the intuition of the artist, and they are not separated acts, as Collingwood ([1938] 1958) argued. In my craft productions, the eye and the mind concentrated on the rhythm of the hand twisting, looping and pulling paper string, deciding what rhythm the hand should perform in relation to the knotting structure, i.e., how hard to pull the strings and how fast the cycle of twisting, looping and pulling could be. Once the rhythm in the creative process had become constant, concentration would remain on an accurate force and speed of manipulating the material. The steady rhythm and concentration make the motion of the making hand firmly established in the craft artist's mind, so that she can see beforehand what the hand is going to do (Sennett 
2008: 176). The consciousness of the craft artist is therefore no longer on what her hands are doing, but on what she sees and expects to see in the future.

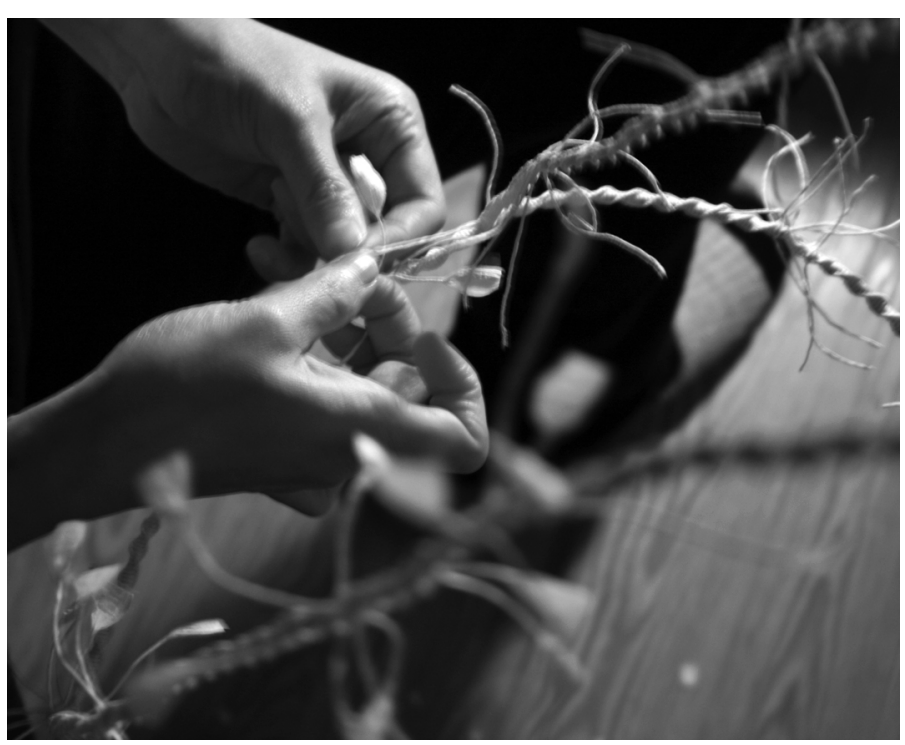

Figure 8: Nithikul Nimkulrat (17 October 2006), The hands manipulate paper string, photograph by Thomas Reichler, (c) Nithikul Nimkulrat.

These conclusions are extended by phenomenological thinking (Heidegger [1988] 1999; 2001: 17-86; Merleau-Ponty [1962] 2005), which explains why the experience of an artwork is inseparable from all kinds of entities surrounding it. All the things present in a place affect and form the experience of being there. Touching, seeing and interpreting are experiential acts of both the artist and viewers that never happen by concentrating on a single thing alone. As can be seen in 'Paper World', its creation - influenced by phenomenological thinking considered the relationship of all craft artworks to the overall exhibition. On the one hand, when one type of material was employed in every work, its ubiquity grounded a relationship between the works, creating the wholeness of the exhibition. On the other, the context informed the craft artist how the parts (material and craft artworks) should be composed to highlight the relationship between them. Understanding the materialness of the chosen medium hence concerns the understanding of the whole, which includes the following factors: the creative processes, the forms of the works into which the material is transformed, and the context in which the transformed material is displayed and interpreted. The creation of meaningful craft art therefore includes the formation of experience with the overall exhibition, artworks and their material. 
The study has also shown that meaning, which the craft artist embodies in a craft artwork through material manipulation, can differ from that which the viewers might perceive. The reason may involve different natures between the artist's and the viewers' experience. On the one hand, the artist can thoroughly experience a material artwork through the senses of touch and sight, whereas the viewers can experience the same work from a distance - mainly through the sense of sight and movement around the work. On the other, the artist's personal life experience may differ from that of the viewers. However, the viewers can perceive the meaning that the craft artist embodies in her work, especially when the craft artist undertakes the role of a viewer during the creative process. This way of working aims to find similarities between the artist's and the viewers' experiences. For instance, as most visitors of 'Seeing Paper' perceived its meaning differently from the intended meaning, I designed the creative process of 'Paper World' to include the element of an exhibition context and adopt the role of a viewer into the process. Creating craft artworks from a viewer's viewpoint, I exemplified the concept of home in the works and considered other elements in addition to the material at hand. Home is a concept and environment that most people can perceive and understand its meaning. Because of this, most visitors to 'Paper World' were able to understand the intended meaning of the work and the exhibition. Although it is not always important that the viewers understand the exhibits in the same way as the craft artist does, the exhibition offers an opportunity to test whether her expression can come across clearly enough. An exhibition can thus be used as a practical means to improve one's artistic practice and to better understand one's viewers.

\section{Applying materialness to textile pedagogy}

The conception of materialness as well as the approaches and means of documentation used in this research have proven useful for teaching the textile study programme at the University of Art and Design Helsinki. Teaching textile students the conception of materialness does not mean that they should no longer learn traditional textile techniques. Quite the opposite, textile students should still learn and obtain basic skills in making textiles, and simultaneously understand the materialness or thinking through materials concept. Students can achieve the understanding of materialness through their sense perception by playing with their chosen medium. Tearing, folding, breaking and other physical activities are means to find a possible technique to manipulate the material. Playing with the medium results in information about 
its physical qualities, such as colourfulness, roughness, sweetness, etc. This understanding can, in turn, stimulate creativity, inspiring the students to establish correlation between the material and something else they have earlier experienced in life. The students can then utilize the correlation to conceive an idea for a craft artwork and manipulate their material accordingly. To facilitate this understanding, the textile pedagogic system needs to include a course on documentation methods adapted from other fields such as ethnography. The system ought to emphasize the articulated reflection of experiential learning, i.e., learning by doing, observing environments, visiting galleries and museums, etc.

Materialness broadens students' views, suggesting another way of creating textiles that begins with a material of special interest without thinking too much about the material used to manipulate it. This way of selecting a material can illuminate unusual, original or new materials for creating textiles, giving students the confidence to create textile art from materials of atypical forms and qualities. The experimental work with a material and its physical qualities can inspire students to try new manipulative techniques. Being open to techniques can inspire the development of new technical skills in relation to the chosen medium. A material can lead the creative process in various possible directions without the limitation of techniques. Techniques can play a role as mixed experimental media that assist students in playing with materials. Placing the main emphasis on a material creates manifold possibilities for creation. Some ideas can be utilized in future creations, especially in the case of a student who tends to keep a diary about her creative process. Materialness can be applied in educating practitioners in various material-based creative practices such as jewellery, interior design, architecture, etc.

\section{Material inspiration workshop}

Based on the concept of materialness, every academic year I hold an intensive workshop called 'material inspiration'. The workshop is a test space, putting research into practice (i.e., teaching). It is a way to review the conception of materialness and to disseminate the findings of academic research.

The participating students (Finnish and international master's degree students) are asked to choose a material with which they have never worked, without thinking much about the techniques or the resulting object and its function. However, they should have personal interest in the material, and be able to explain verbally their reasons for selecting that 
particular material. In addition, I encourage them to have a diary in which they write about their material and creative process, and to photograph their creative process. This not only creates awareness and understanding of their practice, but also improves their skills in discussing the meaning and significance of their work. In the workshops, students regularly come up with various types of material alien to textile art, for example, pasta, yogurt lids, plastic straws, marshmallows, plastic bubble sheet, etc. Students are asked to examine the sensory qualities or characteristics of the chosen materials, e.g. colours, textures, sounds, smells and original functions. This leads students to play with their medium and simultaneously to question themselves about how they feel about the medium at hand, and what comes to their mind when experiencing the medium through their senses. From the qualities the students recognize in the materials, they are guided to find connections between the materials and some other things or stories they had experienced in life, i.e. the association between the physical reality and an imaginative idea. This is a way to think about the material as a metaphor. This metaphorical thinking leads students to find ways or techniques of making art or design works from the newly chosen materials.

The resulting objects made by the students often appear original and interesting. A work I would like to exemplify here is a piece of clothing which represents autumn and which is made of yogurt lids. The student who created this work was interested in aluminium foil lids because of their function, sound, colours and shape. The original function of the lids, to cover yogurt cups, for her evoked the function of clothing to cover human bodies. The sound of the lids touching each other reminded this student of the sound of dry leaves blown by the wind. The colours of the lids, the silver colour of the inner side and the various colours of pictures of fruits printed on the outer, made her think of autumn colours. She categorized the lids according to their colours. She then found out that the round shape of the lid when folded was similar to the shape of a leaf. This student, therefore, folded the aluminium foil lids and composed the folded lids from green to yellow, orange, red and finally white (silver) to represent colour-changing leaves in autumn. She sewed the lids together by hand to form a wearable piece of clothing (figures 10a and $\mathrm{b}$ ). 

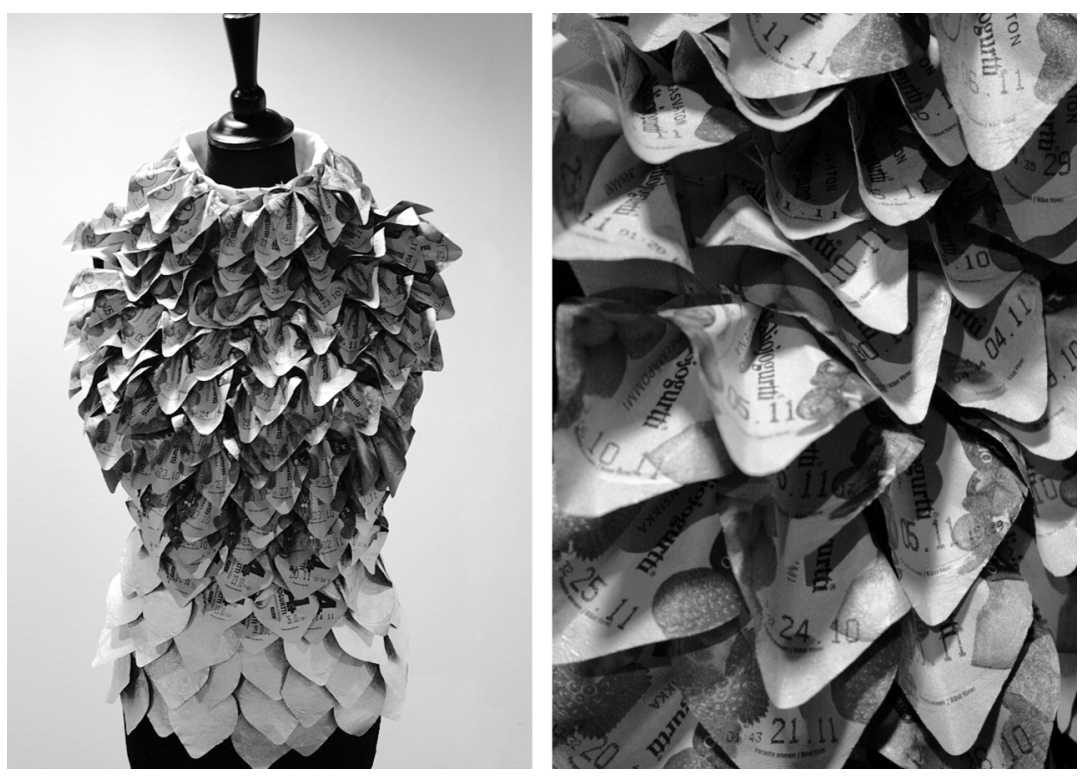

Figures 9a and b: Sayaka Mutsumura (5 December 2007), Leaves left autumn for winterwearable piece made of yogurt lids, photograph by Nithikul Nimkulrat, C Sayaka Mutsumura and Nithikul Nimkulrat.

Judging the results of any student work can be subjective. In the material inspiration workshop, assessment criteria consisted of four key components: (1) understanding of materialness - how the student developed conceptual ideas through play with the chosen material; (2) application of understanding - how the student found original solutions or techniques to manipulate the material and realize their ideas into a craft art/design work; (3) reflection on the process and finished work - how the student used a working diary throughout the creative process and how they reflected on and evaluated their working process, development and complete work; and (4) critical awareness and personal commitment - how the student showed self-motivation and enthusiasm to challenge their own craft practice and to develop further potential. These components suggested that the students' learning progress was followed throughout, from working processes to finished works, working diaries, written texts of works and oral presentations.

\section{Conclusion}

Having demonstrated how materialness could be applied in textile pedagogy, the conception has proven not only to help students to express the meanings of their works but also guide them throughout their artistic processes. It contributes to stimulating students' creativity, so that they are able to conceive meaningful ideas, forms, methods, interpretations, etc. By 
employing this conception in their creation, students become more aware of the meanings of their creative process, i.e. how they control the interplay between material and techniques, in order to convey meanings through the object created. In addition, as a logical way of thinking through materials, this conception can be helpful for craft artists to develop their working process. The basic guidelines for other makers to achieve the understanding of materialness include the following: (1) the core of any creative process is placed on the chosen material thinking about techniques, functions, forms and concepts comes later. (2) Experimenting with the material and thinking through it can be sustained by the use of mind maps or chronological narratives in a working diary. Keywords from the diary can help the craft artist gradually find appropriate techniques, functions, forms and concepts for the resultant works.

(3) Working diaries and other means of documentation can be used to facilitate the process of thinking through materials. To do this effectively, they ought to be carried out regularly and systematically, e.g. stating on a daily basis when there are changes in the creative processes, with date and time specified.

Creative practice in a research context can generate new knowledge, which is embedded in the practice and embodied in and by the practitioner. This knowledge can be found not only in the practitioner making the artefact, but also in the artefact created, the process used to make it, and the culture in which it is made and viewed or used. Understanding all of these elements of practice in an actual artistic experience can begin as personal awareness, which may be detailed, proven and generalized, so that a new way of understanding in the field emerges and can be disseminated. The 'material inspiration workshop' is an example of how knowledge gained from practice-led research in craft art can be useful for novice practitioners in the field.

\section{References}

Adamson, Glenn (2007), Thinking through Craft, Oxford: Berg.

Andrew, Sonja (2008), 'Textile Semantics: Considering a Communication-based Reading of Textiles', Textile: The Journal of Cloth and Culture, 6: 1, pp 32-65. 
Collingwood, Robin George ([1938] 1958), The Principle of Art, Oxford: Oxford University Press.

Cross, Nigel (1982), 'Designerly Ways of Knowing', Design Studies, 3: 1, pp 221-227.

Cross, Nigel (1999), 'Designerly Ways of Knowing: Design Discipline Versus Design Science', Design Issues, 17: 3, pp 49-55.

Dewey, John ([1925] 2003), Experience and Nature, New York: Kessinger Publishing.

Dewey, John ([1934] 2005), Art as Experience, New York: Perigee.

Gale, Colin and Kaur, Jasbir (2002), The Textile Book, Oxford: Berg.

Heidegger, Martin ([1988] 1999), Ontology: The Hermeneutics of Facticity (trans. J. van Buren), Bloomington: Indiana University Press.

Heidegger, Martin ([1971] 2001), 'The Origin of the Work of Art', in Poetry, Language, Thought (trans. Albert Hofstadter), New York: Perennial Classics, pp. 17-86.

Jefferies, Janis (ed.) (2001), Reinventing Textiles vol. 2: Gender and Identity, Bristol: Telos.

Kruskopf, Erik (1975), Finnish Design 1875-1975: 100 Years of Finnish Industrial Design, Helsinki: Otava.

Lukkarinen, Leena (2008), Kierrätysmateriaalin käyttö nykytekstiilitaiteessa. Tulkintoja kierrätetystä tekstiilimateriaalista naiseuden ja arjen valossa/ The Use of Recycled Material in Contemporary Fibre Art: Interpretations of Recycled Textile Material in the Light of Womanhood and the Everyday Life, Helsinki: University of Art and Design Helsinki.

Merleau-Ponty, Maurice ([1962] 2005), Phenomenology of Perception (trans. C. Smith), London: Routledge Classics. 
Nimkulrat, Nithikul (2007a), 'Seeing the Seeing Paper: Looking at Personal Artistic Experience through Artefacts', University of Art and Design Helsinki Working Papers, 32, pp. 17-24.

Nimkulrat, Nithikul (2007b), 'The Role of Documentation in Practice-led Research', Journal of Research Practice, 3: 1, http://jrp.icaap.org/index.php/jrp/article/view/58/83. Accessed 2 January 2010.

Nimkulrat, Nithikul (2009), Paperness: Expressive Material in Textile Art from an Artist Viewpoint, Helsinki: University of Art and Design Helsinki.

O'Doherty, Brian (1999), Inside the White Cube: The Ideology of the Gallery Space, Berkeley: University of California Press.

Priha, Päikki (1999), 'From Weave to Fibre', in Visions of Modern Finnish Design, (ed. Anne Stenros, trans. John Arnold and Jüri Kokkonen), Helsinki: Otava, pp. 120-131.

Risatti, Howard (2007), A Theory of Craft: Functional and Aesthetic Expression, Chapel Hill: University of North Carolina Press.

Rowley, Sue (ed.) (1999), Reinventing Textiles vol. 1: Tradition and Innovation, Bristol: Telos.

Rust, Christ, Mottram, Judith and Till, Jeremy (2007), AHRC Research Review: Practice-led Research in Art, Design and Architecture, London: Art \& Humanities Research Council.

Schön, Donald Alan ([1983] 1995), The Reflective Practitioner: How Professionals Think in Action, New York: Basic Books.

Sennett, Richard (2008), The Craftsman, New Haven: Yale University Press.

Singleton, Fred (1986), The Economy of Finland in the Twentieth Century, Bradford: University of Bradford. 
Sharrad, Paul and Collett, Anne (eds.) (2007), Reinventing Textiles vol. 3: Postcolonialism and Creativity, Bristol: Telos.

\section{List of illustrations}

Figure 1: Nithikul Nimkulrat (2 February 2009), Diagram of the dialogue between research approaches, means of documentation and data collection, (C) Nithikul Nimkulrat.

Figure 2: Nithikul Nimkulrat (5 June 2005), 'Seeing Paper', photograph by Maj Lundell, (C) Nithikul Nimkulrat.

Figure 3: Nithikul Nimkulrat (7 February 2007), 'Paper World', photograph by Phakphum Julnipitawong, (C) Nithikul Nimkulrat.

Figures 4a, b and c: (19 October 2009), Three types of paper string used to create 'Seeing Paper', photograph by Minna Luoma, CNithikul Nimkulrat.

Figures 5a, b and c: Nithikul Nimkulrat (5 June 2005), from left: Let Go, Get Sorted and Breathe Easily (each piece uses one of the three types of paper string presented in figures $4 \mathrm{a}$, $\mathrm{b}$ and $\mathrm{c}$ with the same knotting technique), photograph by Maj Lundell, (C) Nithikul Nimkulrat.

Figures 6a, b and c: Nithikul Nimkulrat (5 June 2005), from left: Private Garden, Private Area and Personal Joy (detail) (each piece uses one of the three types of paper string presented in figures $4 \mathrm{a}, \mathrm{b}$ and $\mathrm{c}$ with a different knotting technique), photograph by Maj Lundell, (C) Nithikul Nimkulrat.

Figure 7: Nithikul Nimkulrat (7 February 2007), The Coal Rake (artwork created and installed with regard to an existing element of the gallery space) photograph by Phakphum Julnipitawong, (C) Nithikul Nimkulrat. 
Figure 8: Nithikul Nimkulrat (17 October 2006), The hands manipulate paper string, photograph by Thomas Reichler, (C) Nithikul Nimkulrat.

Figures 9a and b: Sayaka Mutsumura (5 December 2007), Leaves left autumn for winterwearable piece made of yogurt lids, photograph by Nithikul Nimkulrat, (C) Sayaka Mutsumura and Nithikul Nimkulrat. 